\title{
A RADIO METHOD FOR SYNCHRONIZING RECORDING APPARATUS
}

\author{
By T. Parkinson and T. R. Gilliland
}

\section{ABSTRACT}

A method is described for running two radio fading recorders at the same speed when it is necessary to have one of the recorders portable so that it can be moved to various distances from the other. In the work reported each of the recorder drums was propelled by a synchronous motor of the type used for clocks. Since wire connections were not practicable, the portable recorder was controlled by a radio transmitter placed at the fixed station. The same 60-cycle source of power used to drive the synchronous motor at the fixed station was used to modulate the transmitter, the signal of which was received at the portable station and amplified sufficiently to drive the synchronous motor there. With the transmitter working on low power it was possible to drive the recorders at the same speed when separated by a distance of $16 \mathrm{~km}$. A method is described for marking . the two records simultaneously so that they can be superposed.

The need of synchronizing duplicate recording mechanisms when widely separated in space and when placed in situations which prohibit wire connecting circuits, resulted in the development by the National Bureau of Standards of a simple radio method which may be of interest in other lines of research. When it became desirable to compare graphic fading records of the same radio transmission as measured at two points of varying separation, it was found that no recorders were available which could be depended upon to run independently, and at the same time insure equal speeds of the recording tapes. Where wire connections were permissible, synchronous motors driven by a common power supply were satisfactory, but for the projects in hand it was necessary to have one receiving station complete in itself on a laboratory car, which could be moved to any desired distance. Experiments with spring-driven apparatus and with governor controlled electric motors showed that only at accidental intervals was there sufficient agreement in their speeds to produce pairs of records which could be superposed for comparison. Even slight discrepancies in speed were serious, since the changes studied were often very rapid, sometimes having periods as short as five seconds.

Because synchronous motors of the type used for clocks had given very satisfactory results when supplied by wire from the same source of alternating current, it was thought possible to arrive at the same result by radio. Initial experiments verified this belief, and the system hereinafter described was developed and found satisfactory.

The general method consists of the transmission from a transmitter of the half-wave self-rectifying type with 60 -cycle plate supply, the 
reception and amplification of this transmission in such a manner that the output is sufficient to drive the 6-watt synchronous clock motor, which in turn propels the recorder drum through a system of gears. The same 60-cycle supply which is stepped up in voltage to supply the plate of the transmitting tube is also used directly to operate a second synchronous motor and recorder near the transmitter, suitable reactors and condensers being used in the connecting lines to prevent these conductors from introducing a strong field at the point where receiving measurements are to be made.

Figures 1 and 4 show the connections used at the control station and at the portable station, respectively.

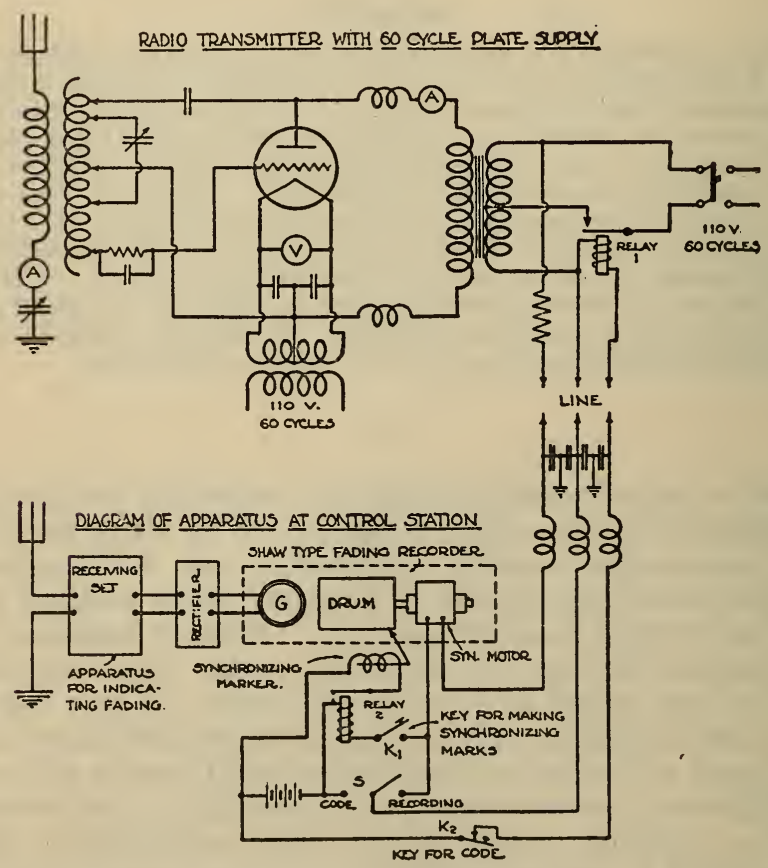

FIGURE 1.-Schematic diagram of apparatus at control station

In order that the records might be superposed for comparison, it was necessary that some method be devised for marking them simultaneously. This was accomplished by attaching a small relay ( $B$, fig. 4) to the iron yoke of the synchronous motor at the portable station in such a manner that the relay is held open as long as alternating current flows in the motor circuit. When the flow is stopped the relay closes the battery circuit, causing a magnetically operated pencil to make a mark on the record. With the circuits as shown in Figure 1 the closing of key $K_{1}$ with switch $S$ in the recording position, causes relay 1 to open the a. c. supply, thus stopping the transmitter and the motor at the control station. The closing of $K_{1}$ also operates relay 2 , thus causing the marker to make a mark on the record; but the stopping of the transmitter also stops the motor at the portable 


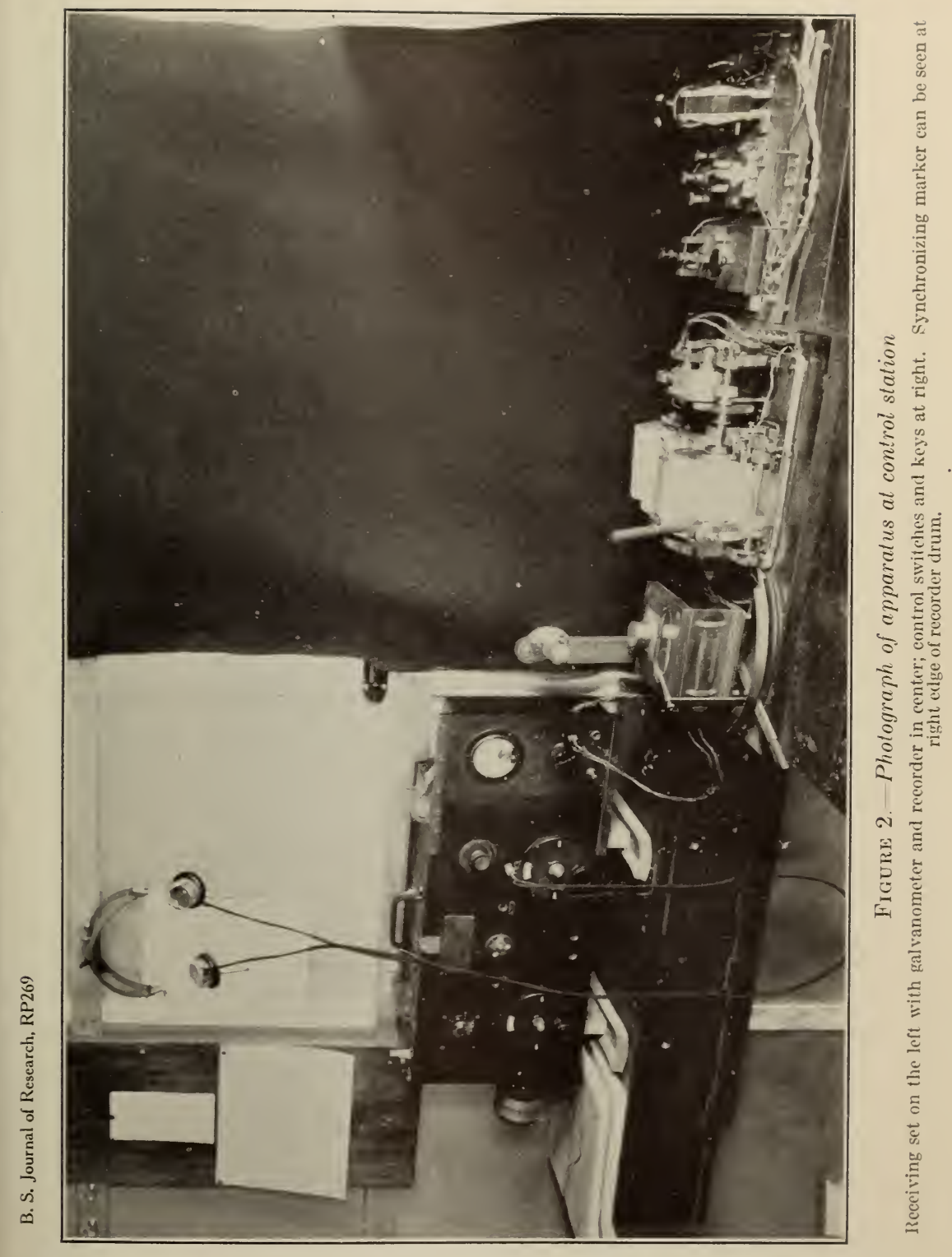




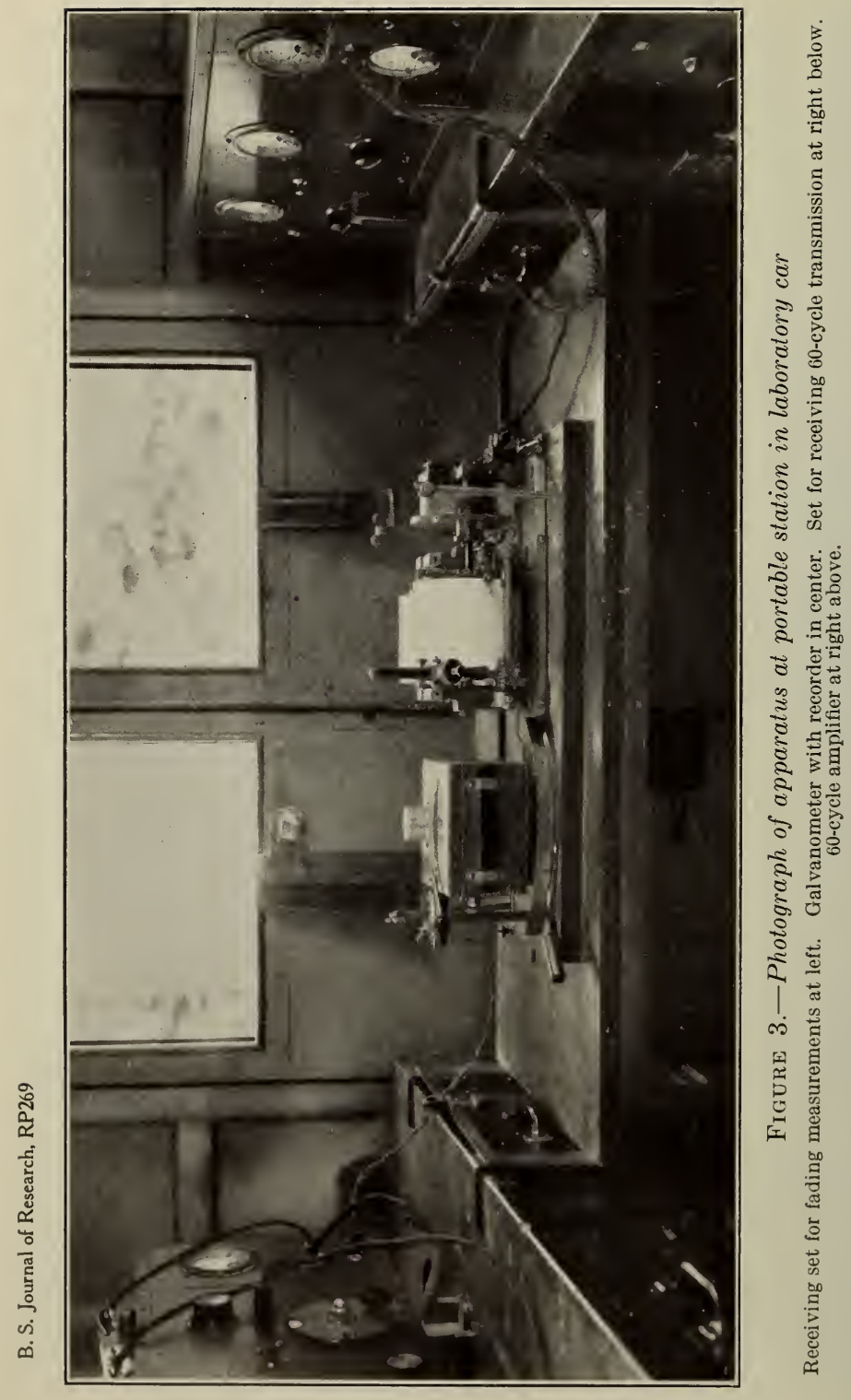


station and causes a mark to be made upon the record there. Thus the closing of $K_{1}$ stops the recorders at both stations and causes marks to be made simultaneously on both records. Both recorders will start out together when $K_{1}$ is opened.

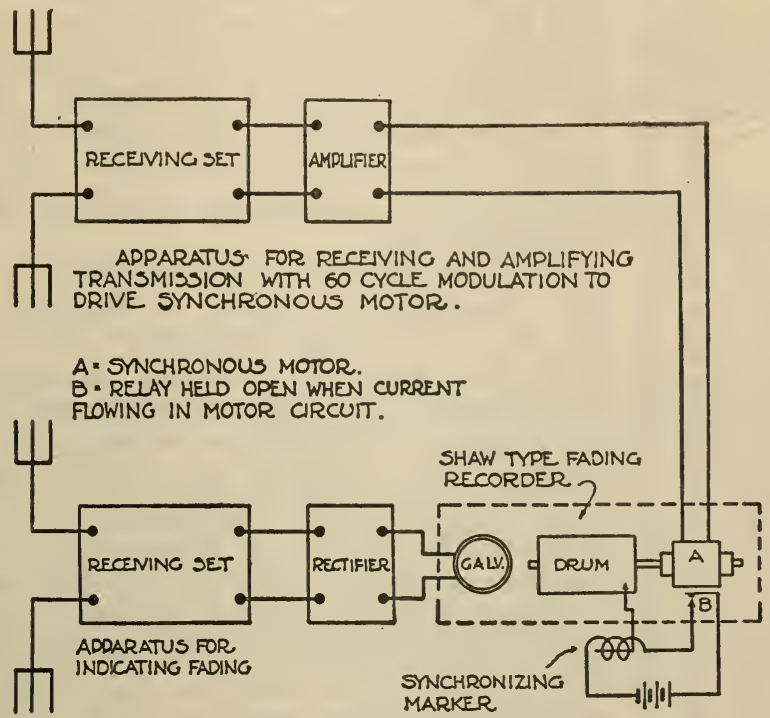

Figdre 4.-Schematic diagram of apparatus at portable station

It is possible to use the same transmitter to communicate by telegraph with the portable station merely by throwing switch $S$ to the left position and operating $K_{2}$.

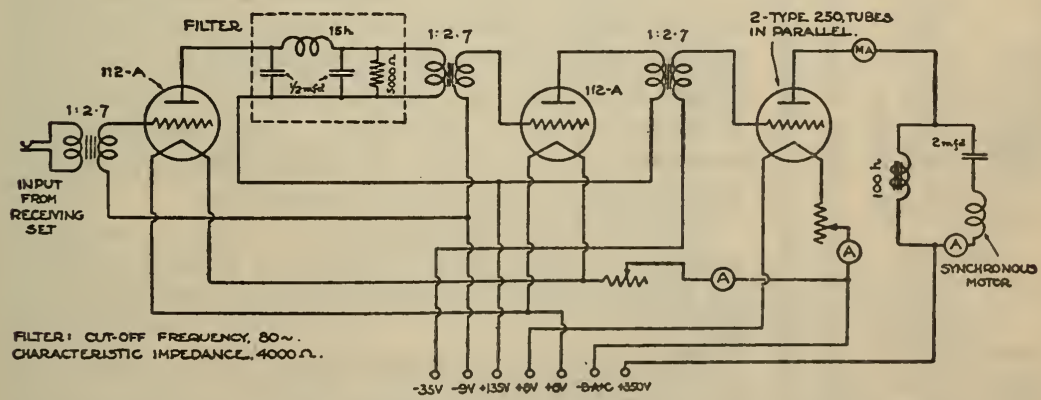

FIGURE 5.-Circuit diagram of amplifier used for driving synchronous clock motor

Figure 5 is a diagram of the amplifier used for driving the synchronous motor at the portable station. Best results were obtained when the condenser in the output circuit was of the size which tuned the series circuit, including the condenser and motor, to 60 cycles. 


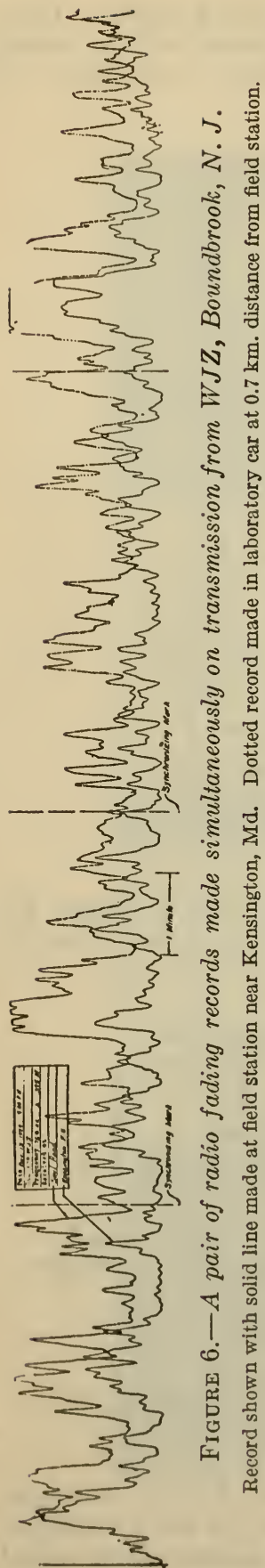

For the motor used, a $2 \mu$ f condenser gave best results. Although it was possible to drive the motor by using only one type 250 tube in the output circuit, more stable operation resulted when two tubes were used in parallel. In testing out the amplifier it was found, by means of an oscillograph, that the motor would operate better as the wave shape of the current approached pure sinusoidal form. In order to eliminate higher harmonics a low pass filter with a cut-off at 80 cycles was placed between the first and second stages.

A single 250-watt tube was used in the Hartley transmitter circuit arrangement shown in Figure 1. The frequency used was near $1,700 \mathrm{kc}$., and was adjusted so that it would not interfere with the near-by receiving measurements. No trouble was experienced in controlling the portable recorder at a distance of $16 \mathrm{~km}$ when the transmitter was operating with small output. If necessary, it should be possible to work at much greater distance.

Figure 6 shows a pair of typical records which have been supcrposed. The record shown with the solid line was made at the control station, while the dotted record was made at the portable station in the laboratory car at a distance of $0.7 \mathrm{~km}$. Both are records of transmission from WJZ, Boundbrook, N. J. (760 kc.), and were made at 9 p. m. eastern standard time, December 13, 1929, near Kensington, Md. The tape speed used was $4.75 \mathrm{~cm}$ per minute.

Although in the arrangement described one of the recording stations was placed near the transmitter and power lines, it would be possible to make it similar to the portable outfit and place it in any desired position. Any number of recorders of the type described might easily be controlled by the same transmitter.

Figure 2 is a photograph of apparatus at the control station, while Figure 3 shows apparatus of the portable station set up in the laboratory car.

The writers wish to acknowledge the valuable assistance given by W. H. Doherty and G. L. Davies in the design and construction of the apparatus.

Washington, September 16, 1930. 